\title{
ERRATUM
}

\author{
Rebecca G. Rogers · Kimberly W. Coates \\ Dorothy Kammerer-Doak $\cdot$ Satkirin Khalsa \\ Clifford Qualls
}

\section{A short form of the Pelvic Organ Prolapse/Urinary Incontinence Sexual Questionnaire (PISQ-12)}

Published online: 7 April 2004

(C) International Urogynecological Association 2004

\section{Int Urogynecol J (2003) 14:164-168}

In the paper above, there were two errors in the short form of the Pelvic Organ Prolapse/Urinary Incontinence Sexual Questionnaire (PISQ-12).

1. The first is in the scoring of the questionnaire. The published version of the questionnaire was written as: "Scores are calculated by totaling the scores for each question with $0=$ never, $4=$ always...To compare the long and short form scores multiply the short form score by $2.58(12 / 31)$ "

The correct version should read: "Scores are calculated by totaling the scores for each question with $\mathbf{0}=$ always and $\mathbf{4}=$ never...To compare the long and short form scores multiply the short form score by 2.58 (31/12)"

2. The second error is in the responses to the first question on the questionnaire. The published version of the question is:

How frequently do you feel sexual desire? This feeling may include wanting to have sex, planning to have sex, feeling frustrated due to lack of sex, etc.

The online version of the original article can be found at http:// dx.doi.org/10.1007/s00192-003-1063-2

R. G. Rogers $(\bowtie) \cdot D$. Kammerer-Doak · S. Khalsa · C. Qualls Department of Obstetrics and Gynecology, University of New Mexico Health Sciences Center,

2211 Lomas Blvd NE, Albuquerque, NM 87131, USA

E-mail: rrogers@salud.unm.edu

Tel.: + 1-505-2729712

Fax: + 1-505-2726385

K. W. Coates

Department of Obstetrics and Gynecology, Scott \& White Clinic, 2401 S. 31st Street, Temple, TX 76508, USA

\author{
Always \\ Usually \\ Sometimes \\ Seldom \\ Never
}

The correct version of the question is:

How frequently do you feel sexual desire? This feeling may include wanting to have sex, planning to have sex, feeling frustrated due to lack of sex, etc.

$\square$ Daily

Weekly

Monthly

Less than once a month

Never

This correct version also matches the version of the long form that is published. (Rogers R, et al. A New instrument to measure sexual function in women with urinary incontinence or pelvic organ prolapse. Am J Obstet Gynecol. March 2001; 184(4): 552-58.) The original psychometric analysis was performed on the correct version of the question. To confirm the validity of studies that may have used the incorrect version, we performed a randomized comparison of the two questions in 19 women with urinary incontinence and/or pelvic organ prolapse. Women answered in random order with a minimum of 3 days between responses one or the other of the two versions. Demographic analysis revealed that the new population did not differ from the original. Comparison of the two versions shows that there was no bias in the direction of disagreement (generalized McNemar, $\mathrm{P}=.97$ ), and that the amount of agreement measured by weighted kappa scores was $.69=/-.12$ (SE). This kappa value did not differ from the original testretest kappa of .73 (t-test, $\mathrm{P}=.75$ ), indicating for this question that the two versions are comparable.I sincerely apologize for these errors. Please do not hesitate to contact me with questions or comments. I can be reached by email rrogers@salud.unm.edu or by phone 505-2729712.Rebecca Rogers, MD 